Forthcoming in Personality and Social Psychology Bulletin

*This article may not exactly replicate the final published version. It is not the copy of record.

\title{
Stereotypes about Political Attitudes and Coalitions among U.S. Racial Groups: Implications for Strategic Political Decision-making
} Maureen A. Craig ${ }^{*}$, Linda X. Zou ${ }^{2}$, Hui Bai ${ }^{3}, \&$ Michelle M. Lee ${ }^{1}$

${ }^{1}$ Department of Psychology, New York University

${ }^{2}$ Department of Psychology, University of Maryland

${ }^{3}$ Department of Psychology, University of Minnesota-Twin Cities

\section{Acknowledgments}

The authors acknowledge support from the National Science Foundation (first author: NSF-BCS2046842; fourth author: NSF-GRFP) and the Washington Institution for the Study of Inequality and Race (second author). We would like to thank the anonymous reviewers and participants at the 2019 New York Area Political Psychology meeting for their helpful feedback on earlier drafts of this manuscript. Finally, many thanks to Mina Cikara and Joshua Cetron for their guidance regarding Multidimensional Scaling.

*Please send correspondence to Maureen A. Craig, Department of Psychology, New York University, 6 Washington Place, New York, NY 10003 (email: maureen.craig@ nyu.edu)

Word count: 10,000 total: 150 (abstract) +8555 (main text + footnotes) +1295 (references) 


\begin{abstract}
What are people's expectations of interracial political coalitions? This research reveals expectations of flexible interracial coalitions stemming from how policies and racial groups are viewed in terms of perceived status and foreignness. For policies seen as changing societal status (e.g., welfare), people expected Black-Hispanic political coalitions and viewed Asian Americans as more likely to align with Whites than with other minorities. For policies seen as impacting American identity (e.g., immigration), people expected Asian-Hispanic coalitions and that Black Americans would align with Whites more than other minorities. Manipulating a novel group's alleged status and cultural assimilation influenced coalitional expectations, providing evidence of causality. These expectations appear to better reflect stereotypes than groups' actual average policy attitudes and voting behavior. Yet these beliefs may have implications for a diversifying electorate, as White Americans strategically amplified the political voice of a racial group expected to agree with their personal preferences on stereotyped policies.
\end{abstract}

Keywords: perceived coalitions, intergroup relations, stereotyping, political psychology 


\section{Stereotypes about Political Attitudes and Coalitions among U.S. Racial Groups: Implications for Strategic Political Decision-making}

In the decade since a multiracial coalition elected the first Black United States president, nearly half of U.S. states enacted voting restrictions that disproportionately reduce racial minority political participation and influence (Weiser \& Feldman, 2018). Many of the most fiercely-debated political issues impact how different groups are positioned in the U.S. racial hierarchy_ both in terms of cultural acceptance and attaining socio-economic resources (e.g., immigration, housing assistance; Pew Research Center, 2014). Understanding people's views of racial groups' policy preferences and coalitional inclinations, and further, how these views may guide support for restricting or enhancing group's political influence is paramount to understanding political dynamics within an increasingly diverse electorate. The present research investigates several key questions regarding people's expectations of racial groups' policy attitudes. First, we investigate perceptions of different racial groups' policy preferences and likelihood of engaging in interracial coalitions for racialized policies seen as impacting American cultural identity and societal status. We then examine whether coalitional expectations are driven by racial stereotypes and if inferred policy preferences match groups' actual average policy attitudes and voting behavior. Finally, we examine downstream consequences of these assumptions and whether White Americans strategically adjust other racial groups' political influence based on racial-political stereotyping.

\section{Cross-racial Mobilization and Expectations of Interracial Coalitions}

Considering research demonstrating that certain political issues tap into voters' sense of group interests and that people seek cross-racial coalition partners who share similar interests and ideology (e.g., Bobo, 1999; Browning et al., 1984), one may expect interracial coalitions to 
stem from perceptions of shared political interest. Indeed, research on cross-racial mobilization - political mobilization of multiple racial groups toward a common cause or candidate - suggests that one predictor of successful cross-racial mobilization is overlap between the policy preferences of a candidate and those of their targeted voter (Collingwood, 2020). An essential question, then, is when are other racial groups' policy preferences seen as similar to one's personal views? The present research asks this antecedent question and tests two theoretically-derived hypotheses regarding individuals' expectations of policy preferences and interracial coalitions among U.S. racial groups.

\section{White-minority Dichotomy}

People's expectations for racial groups' political attitudes may follow a White-minority dichotomy heuristic. Under this hypothesis, different racial minority groups may be expected to support and coalesce with one another (and not with Whites), regardless of the policy under consideration. This prediction stems from research finding that members of culturally-devalued (stigmatized) groups are often expected, and viewed as morally obligated, to support other stigmatized groups (Fernández et al., 2014; Warner \& Branscombe, 2012). Indeed, individuals often expect sympathetic reactions among members of different stigmatized groups (Warner \& Branscombe, 2012) and express surprise if stigmatized groups do not support another victimized group (Fernández et al., 2014). For example, Spanish undergraduates reported expectations that several stigmatized groups (e.g., people with dwarfism, gay people) would be more tolerant toward immigrants, relative to non-stigmatized groups (e.g., young people, bank employees; Fernández et al., 2014). Thus, this work suggests that even for groups stigmatized in very 
different ways, observers hold expectations that simply belonging to a historically-victimized group facilitates and morally obligates intra-minority coalescing.

Other research (Saguy et al., 2020) corroborates this, finding that majority group members perceive that stigmatized groups (compared with non-stigmatized groups) are more committed to supporting and caring for the basic rights of all stigmatized groups (i.e., not solely their own group). In these studies, participants rated that various stigmatized groups (gay men, people with disabilities, Black Americans, and [marginally] Asian Americans) were more committed to broad social justice principles (i.e., equality for all, across forms of inequality), compared with Whites (Saguy et al., 2020). Taken together, this research highlights that a variety of stigmatized groups are expected to be highly committed to social justice on behalf of other minorities. This literature suggests that people may expect members of different racial minority groups to support one another's political interests quite broadly. Thus, this prior work is consistent with the prediction that perceptions of different racial minority groups' political attitudes may be driven by expectations of intra-minority loyalty and broad minority political coalitions.

\section{Policy-stereotype Matching}

An alternative hypothesis is that expectations of racial groups' policy preferences may be shaped by alignment between stereotypic traits associated with racial minority groups and perceptions of the policy domain (policy-stereotype matching). Recent theorizing and empirical data reveal that U.S. racial groups are distinctly stereotyped along two dimensions (Zou \& Cheryan, 2017). Along a dimension of perceived status (i.e., intellectual, economic, and occupational prestige), Black and Hispanic Americans are stereotyped as lower status and inferior relative to Whites, while Asian Americans are perceived to occupy a more intermediate 
position - higher status than Black and Hispanic Americans, but still lower in status than Whites (see also Fiske et al., 2002; Koch et al., 2016). Along the dimension of perceived foreignness"Americanness" (i.e., proximity to the American cultural prototype), Hispanic and Asian Americans are stereotyped as "un-American" and foreign relative to Whites, while Black Americans occupy the intermediate position: perceived as more "American" than Hispanic and Asian Americans, but less so than Whites (see also Dovidio et al., 2010; Kim, 1999).

Given these nuanced racial stereotypes, rather than broad coalitions across racial minority groups, different coalitions may be anticipated depending on the match between racial stereotypes and a policy's perceived relevance to the stereotypic dimensions of perceived status and "Americanness." Indeed, prior work has identified many racialized policies (political issues psychologically linked to racial attitudes, e.g., immigration, welfare; Kinder \& Sanders, 1996; Masuoka \& Junn, 2013; Winter, 2008), but has not examined how the manner in which policies are racialized (due to their perceived impact on social status or American cultural identity) may shape expectancies of groups' policy preferences. Specifically, certain policies seek to influence citizens' social and economic conditions. For instance, policies may propose changes to resource distribution (e.g., welfare, tax policy; Lindert, 2004) or access to employment and educational opportunities (e.g., affirmative action; Bowen \& Bok, 1998). Such status-relevant policies may be perceived to have a greater effect on groups who are disadvantaged along the status dimension. People may thus assume that specific political coalitions will form among stereotypically low-status racial minority groups (e.g., Black-Hispanic coalitions). Racial minority groups seen as higher-status (e.g., Asian Americans) may not be expected to coalesce 
with stereotypically lower-status minorities and, instead, people may expect Asian Americans to politically align more closely with Whites.

Other policies seek to influence the boundaries of "Americanness," whether by limiting or expanding restrictions on who may become an American (e.g., immigration policies;

Tichenor, 2002), or by defining the cultural characteristics that delineate American identity (e.g., official-English policies; Schildkraut, 2003). Groups who are disadvantaged along the foreignness dimension may be perceived to be especially impacted by such policies. Thus, coalitions among stereotypically foreign racial minority groups (i.e., Asian-Hispanic coalitions) may be expected for American identity-related policies. Conversely, racial minority groups stereotyped as relatively more "American" (i.e., Black Americans) may not be expected to coalesce with Asian and Hispanic Americans and, instead, perceived as more closely aligned with White Americans on policies relevant to American identity.

\section{Prior Research Examining Expectations of Racial Groups' Political Attitudes}

The question of whether people's expectations of racial groups' political attitudes are more consistent with the White-minority dichotomy or policy-stereotype matching predictions is unresolved from the extant literature. Research on intermediate groups (groups positioned between at least two outgroups in a hierarchy; Caricati, 2018) is primarily tested with occupational or minimal groups, but suggests that relatively advantaged racial minority groups (e.g., Asian Americans and Black Americans in status and cultural domains, respectively) could conceivably coalesce with either higher-rank (Whites; policy-stereotype matching) or lower-rank (other minorities; White-minority dichotomy) groups.

Political science research reveals that voters often perceive racial minority political candidates as more liberal than White candidates and more liberal than what is accurate based on 
candidates' voting records (Fulton \& Gershon, 2018; Hutchings \& Valentino, 2004; Jacobsmeier, 2015; McDermott, 1998). However, this research often compares only White and Black political candidates and the relatively scant research examining perceptions of Hispanic and Asian American candidates is nuanced. For example, Jones (2014) found that fictitious Black and Hispanic politicians were perceived as more liberal and more likely to be Democrats than otherwise-identical White politicians. Further, when candidates' partisanship was known, White Americans rated Asian and White Democrats as more politically moderate than Black and Hispanic Democrats, above and beyond candidates' actual ideological positions (as approximated by financial donations; Visalvanich, 2017a, 2017b). These results are consistent with psychological research finding that Hispanic and Black Americans (non-politicians) are regarded as more liberal than either Whites or Asian Americans (Chambers et al., 2013). However, other research suggests that racial minorities as a whole are more frequently associated with the Democratic Party, while Whites are more associated with Republicans (Rothschild et al., 2019). Taken together, prior research reveals mixed evidence regarding individuals' expectations of racial groups' political attitudes.

Past research has focused on White Americans' expectations of politicians' general ideology or partisanship. Thus, it remains unclear how different racial groups may view one another's policy preferences and coalitional inclinations on a variety of racialized policies, and further, the implications of these expectations for political-decision making outside of the voting context. Given the ambiguities within the existing literature and considerable applied value of understanding these perceptions, the present research aims to a) ascertain individuals' expectations of racial groups' political attitudes and interracial coalitions surrounding different policies, b) test whether these assumed coalitions actually occur in real-world contexts, and c) 
examine the implications of racial-political stereotypes for strategic decision-making to alter the political influence of different racial electorates.

\section{Overview of Research}

Five studies investigate people's expectations for interracial coalitions and policy support among the largest U.S. racial groups (Studies 1-3) as well as whether expectations align with the actual policy positions and voting behavior of these groups (Studies $2 \& 4$ ). The White-minority dichotomy hypothesis would be supported if individuals expect Whites' policy attitudes to differ from a broad racial minority coalition, regardless of the policy under consideration. The policystereotype matching prediction would be supported if people expect groups disadvantaged in a domain to coalesce (Black-Hispanic coalitions for status-related policies, Hispanic-Asian coalitions for American-identity-related policies), and the intermediate-status minority group (Asian Americans and Black Americans, respectively) to align more with Whites than other minorities. Study 5 tests for consequences of these expectations and whether Whites strategically amplify or diminish the influence of different racial electorates to advance their own policy preferences. See https://osf.io/vqj2n for study data/code.

\section{Study 1}

Given that the policy-stereotype matching hypothesis requires determining which policies are racialized along the dimension of American identity and which are racialized along status, the first aim of Study 1 was to examine how political issues are perceived along these dimensions. Study 1 also provided an initial test of the relative performance of the Whiteminority dichotomy and policy-stereotype matching predictions in capturing expectations of racial groups' policy support.

\section{Method}




\section{Participants}

One hundred and ninety-nine U.S. citizens (96 women, 103 men; 72.9\% White, 12.6\% Black, 5.5\% Asian, 5.0\% Hispanic, 1.5\% Native American, 2.5\% multiracial; $M_{\mathrm{age}}=36.06$, $S D_{\text {age }}=11.25$ ) were recruited from MTurk.com in exchange for $\$ 1$. This sample size has $80 \%$ power to detect small-to-medium effects $(|r| \geq 0.20)$.

\section{Procedure and Measures}

After informed consent, participants rated how much (1=Not at all, $7=$ Very $m u c h)$ different policies would impact societal status and American identity. Participants viewed a list of policies (e.g., increasing immigration; see Table 1) and were asked a) "How much would implementing these changes to the following policy issues influence people's levels of status, resources, or prestige in society?" and b) "How much would implementing these changes to the following policy issues influence who fits in American culture and identity, or who is seen as American?" Higher numbers indicate greater perceptions that the policy impacts societal status and American cultural identity, respectively.

Participants then indicated their best guesses of the degree to which several U.S. racial groups (White Americans, Black Americans, Hispanic Americans, Asian Americans) support those policies (1=Strongly oppose, $7=$ Strongly in favor). Higher numbers indicate expectations of more support. Finally, participants completed demographic questions (e.g., race, age), were compensated, and debriefed.

\section{Results}

\section{Ratings of Policies}

As fully-reported in the Supporting Information, policies relating to monetary resources and education (i.e., welfare, low-income housing availability, affirmative action, taxes on the 
wealthy) were seen as impacting societal status more than American identity. In contrast, participants viewed policies relating to immigration and language (i.e., increasing immigration, deporting undocumented immigrants, making English the official language) as more influential on American identity than societal status.

\section{Expected Policy Support}

We conducted a series of repeated-measures analyses of variance (ANOVAs) on perceived policy support with target racial group as the within-subjects factor (see Table 1 for descriptive statistics). All omnibus tests of whether expected policy support differed by racial group under evaluation were significant $\left(p s<.001, \eta_{\mathrm{p}}^{2} \mathrm{~s}\right.$ ranged .11-.52; see Supporting Information). 
Table 1. Descriptive statistics for perceptions that racial groups support and are affected by racialized policies (Studies 1 \& 2).

\begin{tabular}{|c|c|c|c|}
\hline $\begin{array}{l}\text { Perceptions of } \\
\text { White }\end{array}$ & $\begin{array}{l}\text { Perceptions of } \\
\text { Asian }\end{array}$ & $\begin{array}{l}\text { Perceptions of } \\
\text { Hispanic }\end{array}$ & $\begin{array}{l}\text { Perceptions of } \\
\text { Black }\end{array}$ \\
\hline Americans & Americans & Americans & Americans \\
\hline$M(S D)$ & $M(S D)$ & $M(S D)$ & $M(S D)$ \\
\hline
\end{tabular}

Increasing welfare resources

Perceived support (Study 1)

Perceived support (Study 2a)

Perceived support (Study 2b)

Perceived to be affected (Study $2 b$ )

$3.41(1.68)^{\mathrm{a}}$
$3.41(1.72)^{\mathrm{a}}$
$3.52(1.58)^{\mathrm{a}}$
$4.08(1.55)^{\mathrm{a}}$

$4.13(1.43)^{\mathrm{b}}$

$4.16(1.49)^{\mathrm{b}}$

$4.06(1.54)^{\mathrm{b}}$

$3.33(1.59)^{\mathrm{b}}$

Increasing low-income housing availability

Perceived support (Study 1)

Perceived support (Study 2a)

Perceived support (Study 2b)

Perceived to be affected (Study 2b)

\section{Decreasing taxes on the wealthy}

Perceived support (Study 1)

Perceived support (Study 2a)

Perceived support (Study 2b)

Perceived to be affected (Study $2 b$ ) $3.65(1.62)^{\mathrm{a}}$

$3.64(1.69)^{\mathrm{a}}$

$3.65(1.51)^{\mathrm{a}}$

$3.86(1.52)^{\mathrm{a}}$

$4.07(1.75)^{\mathrm{a}}$

$3.79(1.94)^{\mathrm{a}}$

$-$

$-$ $4.25(1.38)^{\mathrm{b}}$

$4.40(1.45)^{\mathrm{b}}$

$4.22(1.47)^{\mathrm{b}}$

$3.40(1.64)^{\mathrm{b}}$

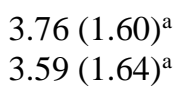

$3.59(1.64)^{\mathrm{a}}$

$-$

Enforcing university affirmative action

Perceived support (Study 1)

Perceived support (Study 2a)

Perceived support (Study 2b)

Perceived to be affected (Study 2b) $3.14(1.52)^{\mathrm{a}}$

$3.56(1.74)^{\mathrm{a}}$

$3.09(1.59)^{\mathrm{a}}$

$4.05(1.74)^{\mathrm{a}}$ $5.46(1.30)^{\mathrm{c}}$

$5.30(1.43)^{\mathrm{c}}$

$5.31(1.40)^{\mathrm{c}}$

$5.11(1.45)^{\mathrm{c}}$

$5.60(1.34)^{\mathrm{c}}$

$5.43(1.37)^{\mathrm{c}}$

$5.56(1.28)^{\mathrm{c}}$

$5.20(1.44)^{\mathrm{c}}$

$2.91(1.84)^{\mathrm{b}}$

$3.00(1.91)^{\mathrm{b}}$

$-$ $5.68(1.13)^{\mathrm{c}}$

$5.41(1.45)^{\mathrm{c}}$

$5.55(1.30)^{\mathrm{d}}$

$5.34(1.48)^{\mathrm{d}}$

$5.86(1.13)^{\mathrm{d}}$

$5.65(1.38)^{\mathrm{d}}$

$5.66(1.38)^{\mathrm{c}}$

$5.42(1.45)^{\mathrm{c}}$

$2.81(1.90)^{\mathrm{b}}$

$2.90(1.96)^{\mathrm{b}}$

$-$

$-$

\section{Establishing English as the national language}

Perceived support (Study 1)

Perceived support (Study 2a)

Perceived support (Study 2b)

Perceived to be affected (Study 2b)

Increasing number of immigrants

Perceived support (Study 1)

Perceived support (Study 2a)

Perceived support (Study 2b)

Perceived to be affected (Study $2 b$ ) $5.61(1.35)^{\mathrm{a}}$

$5.76(1.44)^{\mathrm{a}}$

$5.63(1.47)^{\mathrm{a}}$

$3.17(2.03)^{\mathrm{a}}$

$3.07(1.68)^{\mathrm{a}}$

$3.03(1.72)^{\mathrm{a}}$

$2.90(1.49)^{\mathrm{a}}$

$4.09(1.83)^{\mathrm{a}}$

\section{$4.53(1.56)^{\mathrm{b}}$}

$4.48(1.59)^{\mathrm{b}}$

$4.61(1.67)^{\mathrm{b}}$

$4.36(1.66)^{\mathrm{a}}$ $5.15(1.51)^{\mathrm{c}}$

$4.93(1.39)^{\mathrm{c}}$

$5.11(1.46)^{\mathrm{c}}$

$5.08(1.47)^{\mathrm{b}}$

$5.65(1.41)^{\mathrm{d}}$

$5.35(1.43)^{\mathrm{d}}$

$5.54(1.51)^{\mathrm{d}}$

$5.48(1.66)^{\mathrm{c}}$

Increasing resources for deporting undocumented immigrants

Perceived support (Study 1)

Perceived support (Study 2a)

Perceived support (Study 2b)

Perceived to be affected (Study 2b) $4.45(1.77)^{\mathrm{a}}$

$4.90(1.81)^{\mathrm{a}}$

$4.72(1.68)^{\mathrm{a}}$

$3.45(1.92)^{\mathrm{a}}$

\section{$5.10(1.35)^{\mathrm{b}}$ \\ $4.76(1.44)^{\mathrm{b}}$ \\ $4.90(1.47)^{\mathrm{b}}$ \\ $4.54(1.63)^{\mathrm{b}}$}

$2.64(1.56)^{\mathrm{c}}$

$3.03(1.72)^{\mathrm{c}}$

$2.95(1.72)^{\mathrm{c}}$

$5.26(1.58)^{\mathrm{c}}$

$5.77(1.35)^{\mathrm{c}}$

$5.36(1.62)^{\mathrm{c}}$

$5.50(1.58)^{\mathrm{c}}$

$5.58(1.55)^{\mathrm{c}}$ $4.47(1.58)^{\mathrm{d}}$

$4.54(1.55)^{\mathrm{d}}$

$4.73(1.56)^{\mathrm{d}}$

$2.81(1.70)^{\mathrm{d}}$

$3.97(1.43)^{\mathrm{d}}$

$3.99(1.50)^{\mathrm{d}}$

$3.82(1.54)^{\mathrm{d}}$

$3.41(1.72)^{\mathrm{d}}$

Note. Different superscripts in each row indicate statistically significant (Bonferroni-adjusted) differences between target racial groups. 
To examine our primary research question, we conducted contrast analyses (Furr \& Rosenthal, 2003a) to test whether individuals' expectations are more consistent with beliefs that Whites' policy attitudes diverge broadly from racial minorities' (White-minority dichotomy) or whether more flexible patterns of expected policy support emerge, depending on the domain under consideration (policy-stereotype matching). Standardized contrast weights were used to create indices of how well participants' data fit the different predictions. The difference score between these indices provides the primary outcome measure. Positive values indicate that the policy-stereotype matching prediction fits the data better than the White-minority dichotomy prediction (negative values indicate relatively better fit for the White-minority dichotomy prediction). We conducted one-sample $t$-tests (against 0 ) on these difference scores to determine which (if any) theorized pattern better fits participants' reported expectations of racial groups' political attitudes.

Overall, participants' expectations were more consistent with policy-stereotype matching than a White-minority dichotomy. For policies identified as more status-relevant (e.g., welfare, low-income housing, tax policy), participants were more likely to report that White and Asian Americans would hold similar policy attitudes apart from Black and Hispanic Americans' expected attitudes, than report that White Americans would oppose racial minorities' expected positions: welfare $t(198)=4.14, p<.001, r=.28,95 \% \mathrm{CI}[.15, .41]$, low-income housing $t(198)=5.31, p<.001, r=.35,95 \% \mathrm{CI}[.23, .47]$, tax policy $t(198)=3.00, p=.003, r=.21,95 \% \mathrm{CI}[.07$, .34]. Put another way, participants indicated that Asian Americans' positions on status-related policies were more similar to those of Whites than to other racial minorities. In one interesting exception, participants' perceptions of racial groups' support of affirmative action marginally 
better reflected the White-minority dichotomy pattern of results in which White Americans were expected to oppose affirmative action more than Hispanic, Black, and Asian Americans, $t(198)=$ $-1.75, p=.082, r=-.12,95 \% \mathrm{CI}[-.26, .02]$.

For policies identified as more related to American cultural identity, the policy-stereotype matching pattern also largely fit the data better than expectations that White Americans' support differed from racial minorities'. Analyses revealed that participants reported Black Americans' attitudes to be more similar to those of Whites than to other racial minorities for establishing English as the national language and increasing immigration, $t(198)=2.79, p=.006, r=.19$, $95 \% \mathrm{CI}[.06, .32]$ and $t(198)=3.38, p=.001, r=.23,95 \% \mathrm{CI}[.10, .36]$, respectively. There was no reliable difference in how well these patterns predicted perceptions of racial groups' support for deporting undocumented immigrants, $t(198)=0.67, p=.503, r=.05,95 \% \mathrm{CI}[-.09, .19]$.

\section{Discussion}

Overall, participants' expectations of groups' policy attitudes were more aligned with policy-stereotype matching than with White-minority dichotomy predictions. For policies seen as influencing societal status (e.g., welfare), stereotypically low-status groups (Black and Hispanic Americans) were expected to hold similar attitudes, while the intermediate minority group along the status dimension (Asian Americans) was expected to align more with Whites than other racial minorities. For policies rated as more impactful for American cultural identity (e.g., increasing immigration), the intermediate minority group along the "American" dimension 
(Black Americans) was expected to politically align more with Whites than other minority groups (Hispanic and Asian Americans).

\section{Study 2}

Study 2 replicated and extended the results of Study 1 by including new measures to test perceptions of how much groups are affected by policies as well as a direct measure of perceptions of interracial coalitions. Study 2 also provided an initial test of whether the actual average political attitudes of members of different racial groups align with people's expectations.

\section{Method}

\section{Participants}

Both samples in Study 2 intentionally oversampled racial minorities. ${ }^{1}$ Study 2a included 571 U.S. citizens (340 women, 229 men, 2 non-binary; 48.5\% White, 13.5\% Asian American, 17.2\% Black, 15.1\% Hispanic, 3.7\% Native American/Pacific Islander, 2.1\% multiracial; $\left.M_{\text {age }}=42.91, S D_{\text {age }}=14.16\right)$ recruited online from Prodege. Study $2 \mathrm{~b}$ included 264 U.S. citizens (129 women, 132 men, 3 non-binary; 42.8\% White, 17.0\% Asian American, 17.8\% Black, 13.3\% Hispanic, $6.4 \%$ multiracial; due to an oversight, age was not asked) recruited from MTurk.com for $\$ 1$. These sample sizes have $80 \%$ power to detect small effects $(|r \mathrm{~s}| \geq 0.12$ and 0.17 , respectively).

\section{Procedure and Measures}

After informed consent, participants reported their perceptions that White, Black, Hispanic, and Asian Americans support policies as in Study 1 (1=Strongly oppose, $7=$ Strongly in favor). Additionally, participants in Study $2 \mathrm{~b}$ indicated their perceptions of how much groups are

\footnotetext{
${ }^{1}$ We collected larger, more diverse samples to test whether results were driven by a subset of participants (e.g., White Americans). Limited support for this possibility was found, as participant racial group influenced very few effects ( 3 out of 18 tests; see Supporting Information for these results).
} 
affected by these policies $(1=$ Not at all, $7=A$ lot $)$. Higher numbers indicate that participants perceive groups to be more supportive of and affected by the policies.

In Study $2 b$, participants also completed a sorting task to assess the extent to which they expected coalitions to form among different racial groups. Participants were asked to imagine that the political issues were under debate and coalitions were being formed to advocate for a position [in favor, opposed, would not advocate for a position (neutral)]. Participants sorted racial groups into as many or few coalitions as desired (e.g., all groups could be placed in the "in favor" group). We created variables indicating whether or not $(1=\mathrm{Yes}, 0=\mathrm{No})$ different pairs of racial groups were expected to coalesce.

To test for actual racial group differences in policy support, all participants were asked about their personal support (1=Strongly oppose, $7=$ Strongly in favor $)$ of the same policies. ${ }^{2}$ Finally, participants completed demographic questions (e.g., race), were compensated, and debriefed.

\section{Results}

\section{Expected Policy Support}

As in Study 1, contrast analyses (Furr \& Rosenthal, 2003a) compared the relative fit of the theorized patterns. Consistent with Study 1 and the policy-stereotype matching predictions, participants generally reported greater expectations that Asian Americans' support and the degree to which they are affected by the status-relevant policies were more similar to Whites than to other racial minorities ( $r$ s from .15-.65; see Table 1 and Supporting Information for full analyses). Further, participants reported Black Americans' support and the degree to which they

\footnotetext{
${ }^{2}$ Whether participants reported their expectations about racial groups' political attitudes or their own attitudes first was randomlydetermined in Study 2a; order of presentation did not influence results ( $p \mathrm{~s}>.113)$.
} 
are affected by the American-identity-related policies as more similar to Whites than other racial minorities ( $r$ s from .07-.58; see Supporting Information). Similar exceptions emerged as in Study 1, with some evidence that participants' expectations for support for affirmative action better reflected a White-minority dichotomy (vs. policy-stereotype matching); however, this was only statistically significant in Study $2 \mathrm{~b}$. There was also mixed evidence for how well the different patterns predicted perceived support for deporting undocumented immigrants (see Supporting Information).

\section{Expected Interracial Coalitions}

We examined whether individuals reported that different racial groups would coalesce (Study 2b) more often than would be expected by chance (33\%) via $\chi^{2}$ tests. As shown in Figure 1 , for each policy seen as status-relevant, participants reported consistent expectations of BlackHispanic coalitions [Welfare funding: $\chi^{2}(1)=373.36, p<.001$; Low-income housing:

$\chi^{2}(1)=368.34, p<.001$; Affirmative action: $\left.\chi^{2}(1)=288.07, p<.001\right]$ at levels much greater than chance. However, participants sorted Asian-White coalitions more often than chance for only a subset of policies [Welfare: $\chi^{2}(1)=3.84, p=.050$; Low-income housing: $\chi^{2}(1)=17.46, p<.001$ ], suggesting that expectations of coalitions among groups stereotyped as relatively-advantaged in a domain may be weaker than expectations of disadvantaged-group coalitions. 


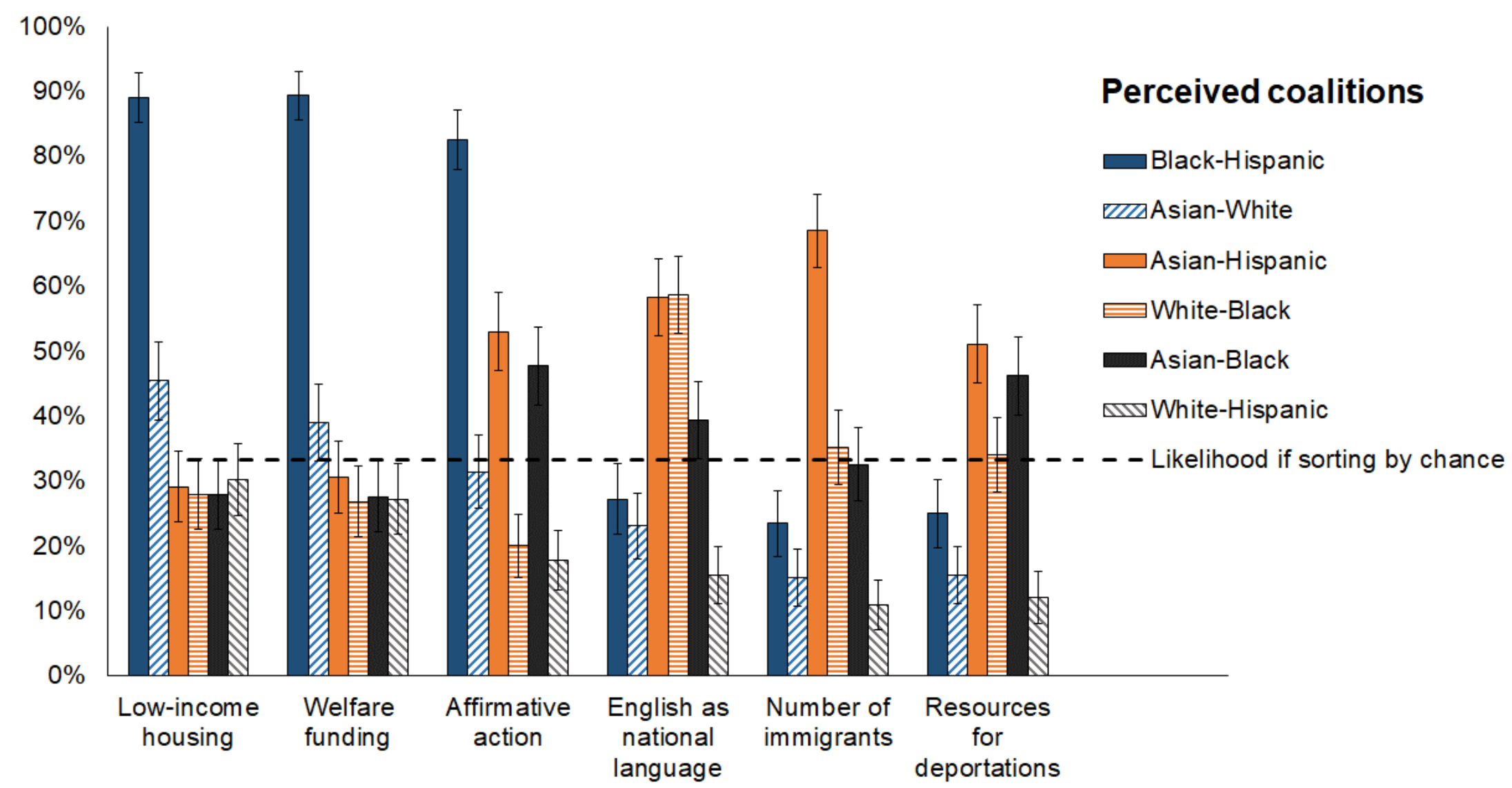

Figure 1. Perceived interracial coalitions for all policies (i.e., with policies seen as changing societal status listed first followed by those seen as changing American identity). The dashed line represents the likelihood that participants would sort two racial groups together in a coalition if deciding by random chance. Error bars represent $95 \%$ confidence intervals around the mean. 
Also shown in Figure 1, participants indicated Asian-Hispanic coalitions more often than would be expected by chance for all policies viewed as relevant to American identity [English as the official language: $\chi^{2}(1)=74.25, p<.001$; Increasing immigration: $\chi^{2}(1)=147.43$, $p<.001$; Deporting undocumented immigrants: $\left.\chi^{2}(1)=37.65, p<.001\right]$. In contrast, WhiteBlack coalitions were reported more often than chance only for the policy of English as the official language, $\chi^{2}(1)=76.52, p<.001$, again suggesting more consistent expectations of coalitions among groups disadvantaged in a domain than of advantaged-group coalitions.

To further examine the coalition-sorting task data, we conducted Individual Difference Scaling (INDSCAL; Borg et al., 2018), grouping by policy type (status-relevant policies, American identity-relevant policies) and applying Procrustean fitting to align the orientations for presentation in Figure 2. Rather than testing a priori theoretical predictions of which coalitions are likely, this analysis provides a data-driven approach that examines how similarly participants sorted different racial groups into coalitions on different policies and represents this visually on a 2-dimensional space. Both INDSCAL solutions achieved excellent fit (Stress indices=.001). Consistent with the $\chi^{2}$ results reported above, this approach revealed that participants sorted Black Americans and Hispanics extremely similarly in terms of expectations of coalescing on status-relevant policies and participants 
sorted Hispanic and Asian Americans very similarly for policies viewed as influencing

American identity (i.e., Figure 2 shows these groups to be in close spatial proximity).

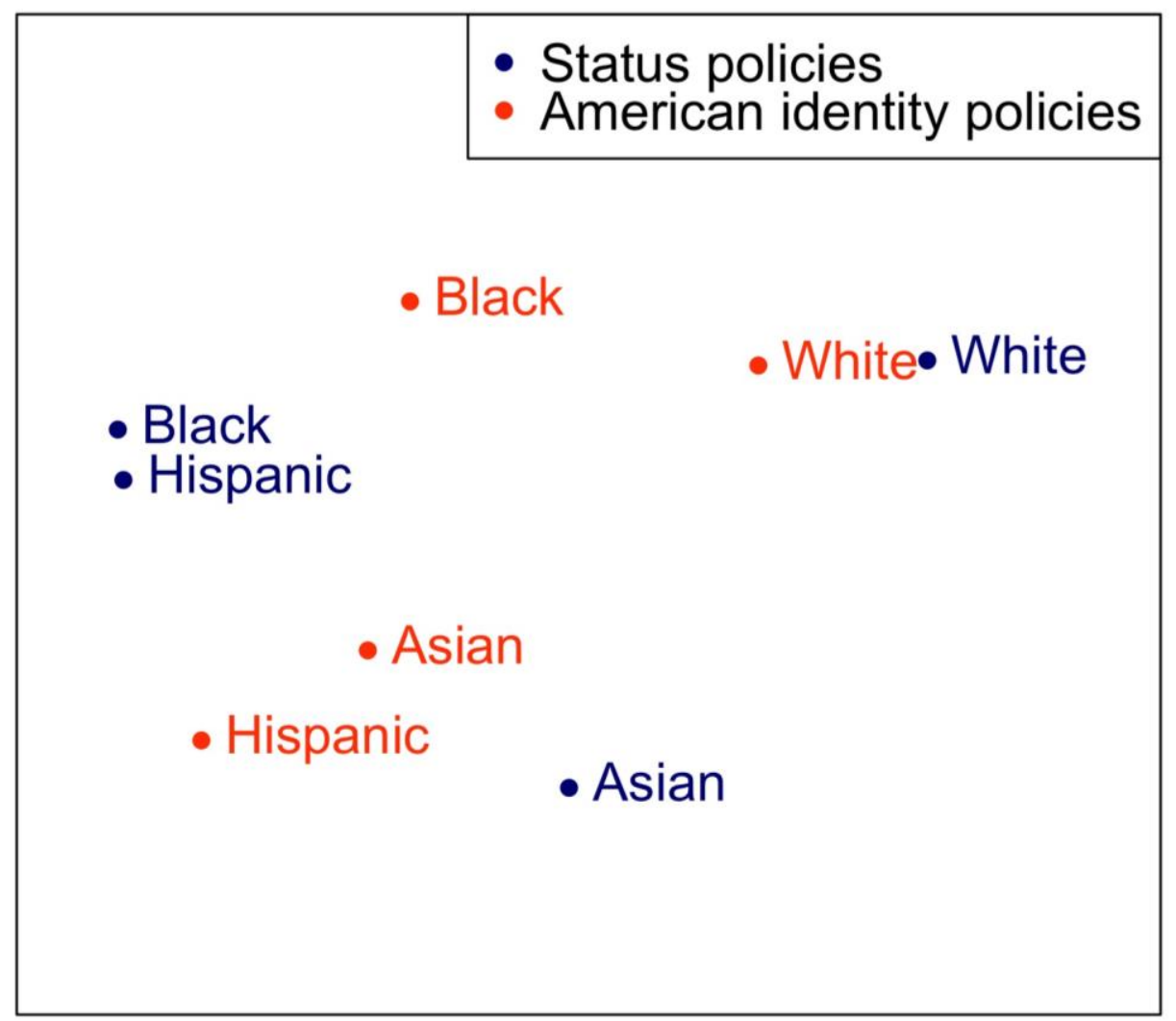

Figure 2. Individual differences scaling plot for coalition sorting data (Study 2b). This presents the extent to which participants placed different U.S. racial groups into coalitions similarly, for policies seen as affecting societal status (darker blue) and those affecting American identity (lighter orange). Spatial distance corresponds to dissimilarity of coalitional sorting, such that groups that are more visually distal are sorted more dissimilarly by participants and groups that are spatially closer are sorted more similarly. 
In contrast, Whites and the intermediate minority group in a domain (Asian Americans for status; Black Americans for "Americanness") were sorted more dissimilarly (visually further apart on Figure 2), compared with the disadvantaged groups. Taken together, results suggest that people more often expected disadvantaged groups to coalesce on a policy, compared with the relatively advantaged groups.

\section{Participants' Own Policy Support}

We conducted a series of ANOVAs on participants' personal policy support with participant racial group as a between-subjects factor and conducted contrast analyses (Furr \& Rosenthal, 2003b), including only individuals who identified as a member of one of the racial groups (White Americans, Asian Americans, Hispanic Americans, Black Americans) about whom we assessed racial-political stereotyping. Contrary to participants' expectations for how racial groups would support different policies, the policy-stereotype matching predictions did not better characterize members of different racial groups' actual expressed policy support (see Supporting Information for descriptive and test statistics). Indeed, the few instances in which different racial groups' policy support fit one theorized pattern better than the other were uniformly more supportive of the possibility that White participants' personal political attitudes diverged from those of racial minority participants.

\section{Discussion}

Overall, the results of Study 2 converge to support the hypothesis that stereotypes of groups' status and "Americanness" guide expectations of how those groups are affected by, support, and will coalesce on policies seen as influencing societal status and American identity. Notably, replicating the unanticipated findings of Study 1, policy-stereotype matching did not 
consistently better fit expectations of groups' support for affirmative action and the deportation of undocumented immigrants, a point we revisit in the General Discussion.

Participants of different racial groups' own policy support did not follow the same patterns as their expectations of groups' support, suggesting that beliefs about groups' political attitudes may reflect stereotypes more than actual group differences. This possibility is explored further in Study 4, but first, we directly investigate the proposition that beliefs about racial groups' expected policy support and likelihood of interracial coalitions are driven by the match between racial groups' perceived status and "Americanness" and the policy's perceived relevance to those stereotypic dimensions.

\section{Study 3}

Studies 1 and 2 demonstrated that expectations for the political and coalitional inclinations of existing racial groups are guided by stereotypes of those groups. Study 3 experimentally manipulated perceptions of the societal status and "Americanness" of a fictitious immigrant group ("Gestavians") for a causal test of whether racial stereotypes drive expectations of policy support and perceived likelihood of coalescing with real racial groups. We predicted that participants would expect an allegedly low-status (vs. high-status) immigrant group (Gestavians) to support policy positions that would challenge the current status hierarchy (e.g., supporting low-income housing) and that Gestavians alleged to be more culturally unassimilated (vs. assimilated) would be expected to support positions challenging the cultural status quo (e.g., opposing establishing English as the official language).

We hypothesized that Gestavians' alleged societal status and "Americanness" would shape expectations of their likelihood of forming coalitions with existing U.S. racial groups. For policies seen as impacting the status hierarchy, participants were predicted to expect allegedly 
low-status Gestavians to coalesce with other stereotypically low-status groups (Hispanic and Black Americans) more than if Gestavians were alleged to be high-status. For policies seen as impacting American cultural identity, participants should expect allegedly foreign Gestavians to coalesce with other stereotypically foreign groups (Hispanic and Asian Americans) more than if Gestavians were alleged to be culturally assimilated. All procedures, hypotheses, and analyses were preregistered (https://aspredicted.org/pc9ba.pdf).

\section{Method}

\section{Participants}

Four hundred and ten White U.S. citizens (259 women, 147 men, 2 other, 2 missing; $\left.M_{\text {age }}=19.51, S D_{\text {age }}=1.97\right)$ were recruited from a large Midwestern university in exchange for partial course credit. ${ }^{3}$ This sample size has $80 \%$ power to detect small effects $(f \geq 0.14)$.

\section{Procedure, Materials, and Measures}

After informed consent and initial demographics (e.g., race), participants read an article presenting information about Gestavians, a fictional U.S. immigrant group. The article was randomly assigned to present Gestavians as either relatively assimilated or unassimilated to American civic and cultural life (alleged "Americanness" manipulation; e.g., "the vast majority (84\%) of Gestavians in the U.S. [have / have not yet] naturalized and [are / are not] United States citizens") and as either relatively high- or low-socioeconomic status (alleged status manipulation; e.g., "Although about $12 \%$ of Gestavians currently live in poverty - this is statistically indistinguishable to that of White Americans (10\%)" vs. "About 26\% of Gestavians currently live in poverty - this is over double the rate for White Americans (10\%)").

\footnotetext{
${ }^{3}$ As described in the preregistration, this data collection was part of a larger collaborative project.
} 
Participants answered two manipulation checks: the first used forced-choice items in which participants indicated whether Gestavians are more culturally similar to Americans or foreigners and whether Gestavians have relatively high- or low-social status. The second check included two items in which participants rated (1=Not at all, $7=$ Very much $)$ how much Gestavians a) fit into American culture and b) have resources, status, and prestige in society.

Participants then reported their expectations of Gestavians' policy support (1=Strongly Oppose, 7=Strongly Support) for five status-related issues (e.g., welfare, the federal minimum wage) and four American identity-related issues (e.g., establishing English as the official U.S. language, increasing immigration). The status policies formed a reliable index $(\alpha=.76)$, but the American-identity policies did not ( $\alpha=.43)$, so, as was preregistered, we examined the Americanidentity policy items separately.

Similar to Study $2 b$, participants also reported the extent to which they expected coalitions to form among racial groups (Asian Americans, Black Americans, Hispanic Americans, White Americans, Gestavians) surrounding four policies (i.e., welfare, low-income housing, establishing English as the official language, immigration). We created variables indicating whether or not $(1=Y e s, 0=N o)$ Gestavians were expected to coalesce a) with Hispanic and Black Americans for status-related policies as well as b) with Hispanic and Asian Americans for American-identity related policies.

\section{Results}

\section{Manipulation Check}

To assess whether the article effectively manipulated participants' views of Gestavians, we conducted 2(alleged "Americanness": assimilated, unassimilated) X 2(alleged status: highstatus, low-status) between-subjects ANOVAs on ratings of perceived status and perceived 
Americanness. ${ }^{4}$ As expected, participants rated Gestavians higher in status and resources if the article presented them as relatively high status $(M=4.78,95 \% \mathrm{CI}[4.62,4.94])$, compared to lower status $\left(M=2.75,95 \%\right.$ CI $[2.58,2.91], F(1,406)=306.23, p<.001, \eta_{\mathrm{p}}{ }^{2}=.43$. A much weaker, unexpected main effect of alleged assimilation emerged on ratings of perceived status (assimilated: $M=3.95,95 \% \mathrm{CI}[3.79,4.11]$; unassimilated: $M=3.57,95 \% \mathrm{CI}[3.41,3.74]), F(1$, 406) $=10.25, p=.001, \eta_{\mathrm{p}}^{2}=.03$. No interaction emerged, $F(1,406)=2.39, p=.123$.

Analyses of perceived "Americanness" revealed that participants rated Gestavians as fitting better into American culture if presented as more assimilated, $(M=5.57,95 \% \mathrm{CI}[5.39$, 5.76]), compared to unassimilated $(M=3.78,95 \% \mathrm{CI}[3.59,3.96]), F(1,406)=180.05, p<.001$, $\eta_{\mathrm{p}}{ }^{2}=.31$. Additionally, a weaker main effect of alleged status revealed Gestavians were rated as fitting better into American culture if they were presented as higher (vs. lower) status, (highstatus: $M=5.02,95 \% \mathrm{CI}[4.84,5.20]$; low-status: $M=4.33,95 \% \mathrm{CI}[4.14,4.52]), F(1,406)=26.48$, $p<.001, \eta_{\mathrm{p}}{ }^{2}=.06$. No interaction emerged, $F(1,406)=1.09, p=.297$. Overall, the manipulations successfully influenced perceptions of the novel immigrant group's status and cultural assimilation strongly $\left(\eta_{\mathrm{p}}^{2} \mathrm{~s}=.31-.43\right)$ in the predicted directions.

\section{Expected Policy Support}

We also conducted 2X2 ANOVAs on expected policy support measures which revealed only the predicted main effects. Consistent with preregistered predictions, participants reported Gestavians to be more supportive of policies that would reduce status differences (and oppose policies that would maintain the status hierarchy) if presented as low-status $(M=5.75$,

\footnotetext{
${ }^{4}$ We chose the continuous manipulation check instead of the force-choice items to retain more data (excluding based on the forced-choice check excludes 154 participants). Regardless, the statistical significance and direction of effects did not differ if using the more exclusionary manipulation check.
} 
$95 \% \mathrm{CI}[5.62,5.88])$, compared with if Gestavians were presented as high-status $(M=4.94$, $95 \% \mathrm{CI}[4.81,5.06]), F(1,405)=76.19, p<.001, \eta_{\mathrm{p}}^{2}=.16$.

For policies related to American identity, consistent with predictions, participants reported Gestavians to be more supportive of making English the official language ( $M=4.03$, $95 \% \mathrm{CI}[3.84,4.22])$ and less supportive of increasing the number of immigrants $(M=5.65$, 95\% CI[5.48, 5.82]) if presented as culturally-assimilated, compared with unassimilated (Englishofficial: $M=2.67,95 \% \mathrm{CI}[2.47,2.86]$; immigration: $M=6.09,95 \% \mathrm{CI}[5.91,6.26]), F(1$, $405)=95.52, p<.001, \eta_{\mathrm{p}}^{2}=.19$, and $F(1,405)=12.50, p<.001, \eta_{\mathrm{p}}{ }^{2}=.03$, respectively. Finally, although directionally consistent, participants' expectations about Gestavians' support for decreasing time needed to apply for citizenship or supporting deportations were unexpectedly not affected by their presentation as culturally assimilated $(M \mathrm{~s}=5.10,95 \% \mathrm{CI}[4.85,5.34], 3.26$, $95 \% \mathrm{CI}[2.98,3.54])$ or unassimilated $(M \mathrm{~s}=5.30,95 \% \mathrm{CI}[5.05,5.55], 2.93,95 \% \mathrm{CI}[2.64,3.21])$, $F(1,405)=1.31, p=.254, \eta_{\mathrm{p}}^{2}=.00$, and $F(1,405)=2.70, p=.101, \eta_{\mathrm{p}}^{2}=.01$, respectively.

\section{Expected Interracial Coalitions}

Logistic regression predicting whether the experimental manipulations and their interaction influenced whether participants sorted Gestavians in the same status-based coalition with Hispanic and Black Americans revealed results consistent with predictions. Participants for whom Gestavians were described as low-status were 4-7 times as likely to indicate that Gestavians would coalesce with Black and Hispanic Americans on the issues of increasing welfare and increasing low-income housing, compared with if Gestavians were described as 
high-status, $b=1.32 \operatorname{SE}(.21)$, Wald $\chi^{2}=38.86, p<.001, O R=3.74,95 \% \mathrm{CI}[2.47,5.67]$ and $b=1.96$ $S E(.25)$, Wald $\chi^{2}=60.35, p<.001, O R=7.10,95 \% \mathrm{CI}[4.33,11.65]$, respectively.

We next tested whether the experimental manipulations and their interaction predicted whether participants sorted Gestavians in the same coalition with Hispanic and Asian Americans on policies related to American cultural identity. Consistent with predictions, participants for whom Gestavians were described as unassimilated were 1.5 times as likely to indicate that Gestavians would coalesce with Asian and Hispanic Americans on making English the official language, compared with if Gestavians were described as assimilated, $b=0.41 S E(.20)$, Wald $\chi^{2}=4.05, p=.044, O R=1.50,95 \% \mathrm{CI}[1.01,2.23]$. Unexpectedly, the alleged assimilation of Gestavians did not significantly influence perceived likelihood of coalescing with Asian and Hispanic Americans to increase immigration, $b=-0.30 S E(.20)$, Wald $\chi^{2}=2.14, p=.143, O R=0.75$, $95 \% \mathrm{CI}[0.50,1.11]$.

\section{Discussion}

Utilizing a novel group paradigm, Study 3 revealed that expectations of groups' policy support and likelihood of coalescing with other disadvantaged groups are driven by perceptions of societal status and cultural assimilation. Specifically, an immigrant group portrayed as lowstatus was expected to support policies that mitigate the status hierarchy and form coalitions with other stereotypically low-status racial groups (Hispanics and Black Americans) more than if the group was portrayed as high-status. If the immigrant group was portrayed as relatively culturallyunassimilated, they were generally expected to support policies that challenge the cultural status quo and form coalitions with other stereotypically-foreign racial groups (Hispanics and Asian Americans) more than if the group was portrayed as culturally-assimilated. Overall, these findings cohere with Studies 1-2 to demonstrate that racial stereotypes about groups' status and 
foreignness drive expectations that disadvantaged groups will coalesce on policies seen as relevant to these dimensions.

\section{Study 4}

Across Studies 1-3, perceptions of racial groups' societal status and "Americanness" shaped expected patterns of policy support and interracial coalition-building, both for existing U.S. racial groups and a fictional immigrant group. One question, particularly relevant for understanding perceptions of existing racial groups, is whether these expectations simply reflect knowledge about racial groups' actual policy attitudes. While the results of Study 2 suggested that racial-political expectations reflect stereotypes more than the recognition of actual group differences, Study 4 pursued ecological validity by using representative samples to test whether the pattern of expectations of political attitudes documented in Studies 1-3 align with actual group policy preferences (Study 4a) and voting behavior in state-wide initiatives (Study 4b).

\section{Method}

\section{Participants}

Study 4a utilized data from the American National Election Studies Time-Series Study (ANES, 2018). We sought to include the largest number of respondents possible and conducted analyses on data from all years that included the policy support questions of interest (19842016). This sample included 31,680 individuals ( $45.5 \%$ men, $54.4 \%$ women, $0.1 \%$ other $/ \mathrm{missing}$ gender information; 23,162 White, 512 Asian American, 3,598 Hispanic, 4,408 Black;

$\left.M_{\text {age }}=47.22, S D_{\text {age }}=17.53\right)$.

Study 4b utilized data from California state election exit polls (1986-2012). California was chosen as it has large minority populations and is often the site of high-profile racialized 
policy initiatives. Across exit polls, the sample includes 15,006 individuals (11,780 White, 615 Asian American, 1,625 Hispanic, 986 Black). ${ }^{5}$

\section{Measures}

Policy Support. In Study 4a, three questions assessed respondents' opinions on federal spending to aid low-income individuals (status policies). Respondents were asked, "Should federal spending on [aid to the poor/welfare programs/food stamps] be increased, decreased, or kept about the same?" (1=Decreased, 2=Kept the same, 3=Increased $)$. Additionally, one policy related to American identity: how the number of immigrants allowed in the U.S. should be changed $(1=$ Decreased a lot, $5=$ Increased a lot $)$.

Voting on Statewide Propositions. In Study 4b, of all statewide propositions with available exit poll data, two initiatives related to status and two related to American culturalidentity (all were passed by voters): a ban on affirmative action (Proposition 209; LA Times, 1996), an initiative increasing high-income households' taxes (Proposition 30; National Election Pool, 2012), an initiative making English the official state language (Proposition 63; LA Times, 1986), and one that restricted undocumented immigrants' use of public services (Proposition 187; LA Times, 1994).

\section{Results}

To facilitate generalizable inferences, analyses used sampling weights when available. As in Study 2, contrast analysis (Furr \& Rosenthal, 2003b) tested whether the data better fit policystereotype matching or White-minority dichotomy predictions.

\section{Policy Support}

\footnotetext{
${ }^{5}$ We excluded individuals who did not vote and individuals who did not identify as Black, Hispanic, Asian, or White.
} 
We conducted weighted subpopulation analyses in Stata (v16.1), regressing policy support on respondents' race (White Americans, Asian Americans, Hispanic Americans, Black Americans), gender, age, educational attainment, and year the survey was conducted. Consistent with the results of Study 2, contrast analysis revealed limited support for the notion that of different racial groups' actual policy preferences better reflect policy-stereotype matching (see Table 2 for descriptive statistics and test statistics). Only one marginal trend emerged such that respondents' support for increasing federal spending on food stamps programs was somewhat better predicted by a policy-stereotype matching pattern, such that Asian Americans reported preferences more similar to Whites' preferences than to Black and Hispanic Americans'. However, the extremely small effect size $(r=.01,95 \% \mathrm{CI}[.00, .03])$ indicates limited practical significance. 
Table 2. Self-reported support for policies (Study 4a) and voting for propositions (Study 4b) by respondent racial group.

\begin{tabular}{|c|c|c|c|c|}
\hline White & Asian & Hispanic & Black & Contrast \\
\hline Americans & Americans & Americans & Americans & analysis \\
\hline
\end{tabular}

\begin{tabular}{|c|c|c|c|c|c|c|}
\hline $\begin{array}{l}\text { Policy } \\
\text { support } \\
(\text { Study 4a) }\end{array}$ & $M_{\text {adj }}(S E)$ & $M_{\text {adj }}(S E)$ & $M_{\text {adj }}(S E)$ & $M_{\text {adj }}(S E)$ & & $r[95 \% \mathrm{CI}]$ \\
\hline $\begin{array}{l}\text { Funding for } \\
\text { welfare }\end{array}$ & $\begin{array}{l}1.67 \\
(0.01)^{\mathrm{a}}\end{array}$ & $1.83(0.04)^{\mathrm{b}}$ & $1.88(0.02)^{\mathrm{b}}$ & $\begin{array}{l}2.06 \\
(0.02)^{\mathrm{c}}\end{array}$ & $\begin{array}{l}F(1, \\
22,276)=0.00 \\
p=.948\end{array}$ & $\begin{array}{l}.00[-.01, \\
.01]\end{array}$ \\
\hline $\begin{array}{l}\text { Funding for } \\
\text { aid to the poor }\end{array}$ & $\begin{array}{l}2.26 \\
(0.01)^{\mathrm{a}}\end{array}$ & $2.40(0.05)^{\mathrm{b}}$ & $2.49(0.02)^{\mathrm{b}}$ & $\begin{array}{l}2.68 \\
(0.01)^{\mathrm{c}}\end{array}$ & $\begin{array}{l}F(1, \\
20,026)=0.70 \\
p=.404\end{array}$ & $\begin{array}{l}.01[-.01, \\
.02]\end{array}$ \\
\hline $\begin{array}{l}\text { Funding for } \\
\text { food stamps }\end{array}$ & $\begin{array}{l}1.77 \\
(0.01)^{\mathrm{a}}\end{array}$ & $1.83(0.06)^{\mathrm{a}, \mathrm{b}}$ & $1.94(0.02)^{\mathrm{b}}$ & $\begin{array}{l}2.23 \\
(0.02)^{\mathrm{c}}\end{array}$ & $\begin{array}{l}F(1, \\
15,721)=2.97 \\
p=.085\end{array}$ & $\begin{array}{l}.01[.00, \\
.03]\end{array}$ \\
\hline $\begin{array}{l}\text { Increasing the } \\
\text { number of } \\
\text { immigrants }\end{array}$ & $\begin{array}{l}2.33 \\
(0.01)^{\mathrm{a}}\end{array}$ & $2.77(0.06)^{\mathrm{b}}$ & $2.74(0.03)^{\mathrm{b}}$ & $\begin{array}{l}2.58 \\
(0.03)^{\mathrm{c}}\end{array}$ & $\begin{array}{l}F(1, \\
18,827)=0.27 \\
p=.602\end{array}$ & $\begin{array}{l}.00[-.02, \\
.01]\end{array}$ \\
\hline
\end{tabular}

$\begin{array}{lllllll}\text { Exit poll data } & \% \text { White } & \text { \% Asian } & \text { \% Hispanic } & \% \text { Black } & \text { Contrast } \\ \text { (Study } 4 \boldsymbol{b}) & \text { American } & \text { American Vote } & \text { American } & \text { American } & \begin{array}{l}\text { Contrast } \\ \text { analysis }\end{array} & \begin{array}{l}\text { analysis } \\ \text { effect } \\ \text { size }\end{array}\end{array}$

Proposition

209:

\begin{tabular}{|c|c|c|c|c|c|c|}
\hline $\begin{array}{l}\text { Banning } \\
\text { affirmative } \\
\text { action }\end{array}$ & $58.1 \%^{\mathrm{a}}$ & $34.8 \% \%^{\mathrm{a}, \mathrm{b}, \mathrm{c}}$ & $37.9 \%^{\mathrm{b}}$ & $14.0 \%^{\mathrm{c}}$ & $\begin{array}{l}z=-0.60, \\
p=.550\end{array}$ & $\begin{array}{l}-.02[- \\
.10, .06]\end{array}$ \\
\hline \multicolumn{7}{|l|}{$\begin{array}{l}\text { Proposition } \\
30 \text { : }\end{array}$} \\
\hline $\begin{array}{l}\text { Increasing } \\
\text { income tax for } \\
\text { high-income } \\
\text { households }\end{array}$ & $49.7 \%^{\mathrm{a}}$ & $61.1 \%{ }^{\mathrm{b}}$ & $52.9 \% \%^{\mathrm{a}, \mathrm{b}}$ & $74.8 \%^{c}$ & $\begin{array}{l}z=-1.27, \\
p=.203\end{array}$ & $\begin{array}{l}-.03[- \\
.06, .01]\end{array}$ \\
\hline $\begin{array}{l}\text { Proposition } \\
63 \text { : }\end{array}$ & $77.7 \%{ }^{\mathrm{a}}$ & $51.8 \%^{\mathrm{b}}$ & $47.2 \%^{\mathrm{b}}$ & $68.4 \%^{\mathrm{c}}$ & $\begin{array}{l}z=1.89 \\
p=.059\end{array}$ & $\begin{array}{l}.03[.00 \text {, } \\
.05]\end{array}$ \\
\hline
\end{tabular}




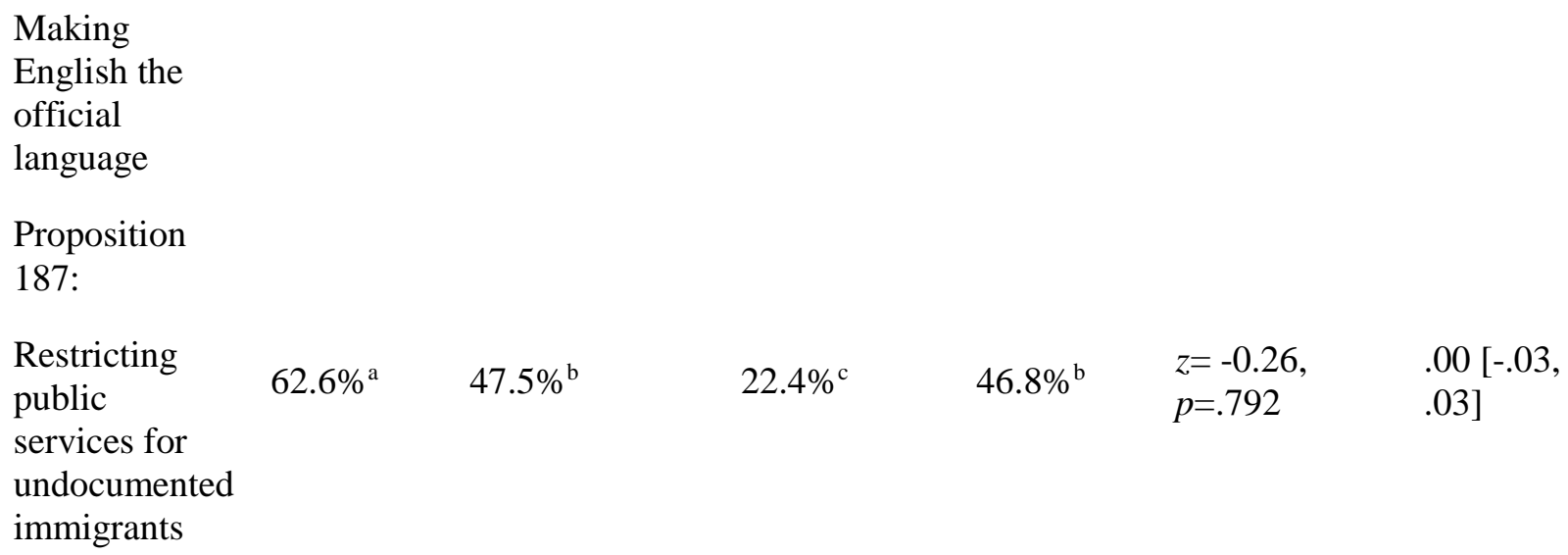

Restricting public $62.6 \%^{\mathrm{a}} \quad 47.5 \%^{\mathrm{b}}$ $22.4 \%^{\mathrm{c}}$ $46.8 \%^{\mathrm{b}} \quad z=-0.26$, $p=.792$

$.00[-.03$, services for undocumented immigrants

Note. Different superscripts within a row indicate statistically significant differences (Bonferroniadjusted) between racial groups. In Study $4 a$, means are adjusted for respondents' age, gender, educational attainment, and survey year. 


\section{Voting on Statewide Propositions}

We compared racial groups' voting patterns for each proposition using a series of $2 \times 4$ omnibus $\chi^{2}$ tests, followed by Bonferroni-adjusted pairwise comparisons of each of the $2 \times 2$ contingency tables. Consistent with the results of Studies 2 and $4 \mathrm{a}$, contrast analyses revealed that different racial groups' voting behavior did not differentially fit either pattern (see Table 2). The one exception was the proposition to make English the official state language, for which a policy-stereotype matching pattern fit marginally better: Black Americans' voting behavior was more similar to the voting behavior of White Americans than to Hispanic and Asian Americans, although again, the effect size was extremely small $(r=.03,95 \% \mathrm{CI}[.00, .05])$.

\section{Discussion}

In light of the consistent findings across Studies 1-3 that expectations of different racial groups' policy support are driven by the match between racial groups' perceived status and "Americanness" and the policy's relevance to those stereotypic dimensions, Studies 2 and 4 suggest that those expectations represent stereotypes more than accurate views of groups' positions. Indeed, Study 4's strengths (in external validity) and limitations (due to lack of control over the wording of questions and ballot initiatives) are complemented by the carefully-matched questions with convenience samples from Study 2. Taken together, these studies provide convergent evidence that different racial groups' actual average policy attitudes and voting behavior may not correspond with stereotypic expectations.

\section{Study 5}

If stereotypes about racial groups' political attitudes do not accurately reflect groups' real-world preferences, might these beliefs still have downstream consequences for political 
decision-making? Regardless of their veracity, individuals may use these stereotypes to make political decisions. For example, Whites who support making English the official language may seek to reduce Asian Americans' political influence and amplify the influence of Black Americans, based on perceptions about how these groups' policy preferences diverge or cohere with their own. Study 4 tests this possibility. White Americans made decisions and allocated resources to Black and Asian American communities for two alleged elections, one surrounding a status-related issue (low-income housing) and one issue relating to American identity (making English the official language). We hypothesized that Whites would strategically make decisions to enhance the political voice of racial groups stereotyped as supportive of their personal political preferences and suppress groups viewed as oppositional to their own preferences.

\section{Method}

\section{Participants}

Four hundred and nine White U.S. citizens (278 women, 130 men, 1 other; $M_{\text {age }}=19.81$, $\left.S D_{\text {age }}=2.67\right)$ were recruited from a large Midwestern university in exchange for partial course credit. This sample size has $80 \%$ power to detect small effects $(|r| \geq .14)$.

\section{Procedure, Materials, and Measures}

After informed consent and initial demographics (e.g., race), participants considered two hypothetical statewide initiatives (increasing low-income housing and establishing English as the official language; order was randomly-determined). Participants indicated their personal support $(1=$ Strongly against it, $7=$ Strongly support $i t)$ and estimated how much racial groups (White Americans, Black Americans, Asian Americans) support (1=Strongly against it, 7=Strongly support it) and are affected by (1=Hurt a lot, 7=Benefit a lot $)$ the initiatives. 
Then, two types of voting (direct popular vote or indirect electoral vote) were briefly described. Participants were asked to select one to determine the initiative's success. Critically, one voting type allegedly increased the political influence of Black Americans (coded as 1) and the other increased Asian American influence (coded as 0; the community benefited by a given voting type was counterbalanced across participants). Participants also indicated where to send volunteers to boost voter turnout: a predominantly-Black community (1) or a predominantlyAsian community (0), as well as what percentage of time should be spent in each community's get-out-the-vote effort (total percentage needed to equal 100). Higher numbers indicate enhancing Black political influence over Asian influence. Finally, participants reported how much time and effort ( $1=$ None at all, $7=$ All of their time $)$ should be devoted to each community to increase turnout, separately. ${ }^{6}$

\section{Results}

\section{Expected Policy Support}

Consistent with Studies 1-3, we found evidence of racial-political stereotyping such that groups were viewed as differentially supportive of and benefited by the initiatives (see Supporting Information for these analyses). As shown in Figures 3-4, Black Americans were viewed as more supportive than Asian Americans of increasing low-income housing (a relatively liberal position on a status-relevant policy) and making English the official language (a relatively conservative position on an American identity-relevant policy). Further, participants rated their own group (White Americans) as less supportive of low-income housing and more supportive of

${ }^{6}$ Participants also selected outreach materials, with confusingly-worded instructions, making results difficult to interpret (see Supporting Information for these results). 
making English the official language than both Black and Asian Americans. Perceptions that groups are benefited by the initiatives mirrored these patterns (see Supporting Information). 


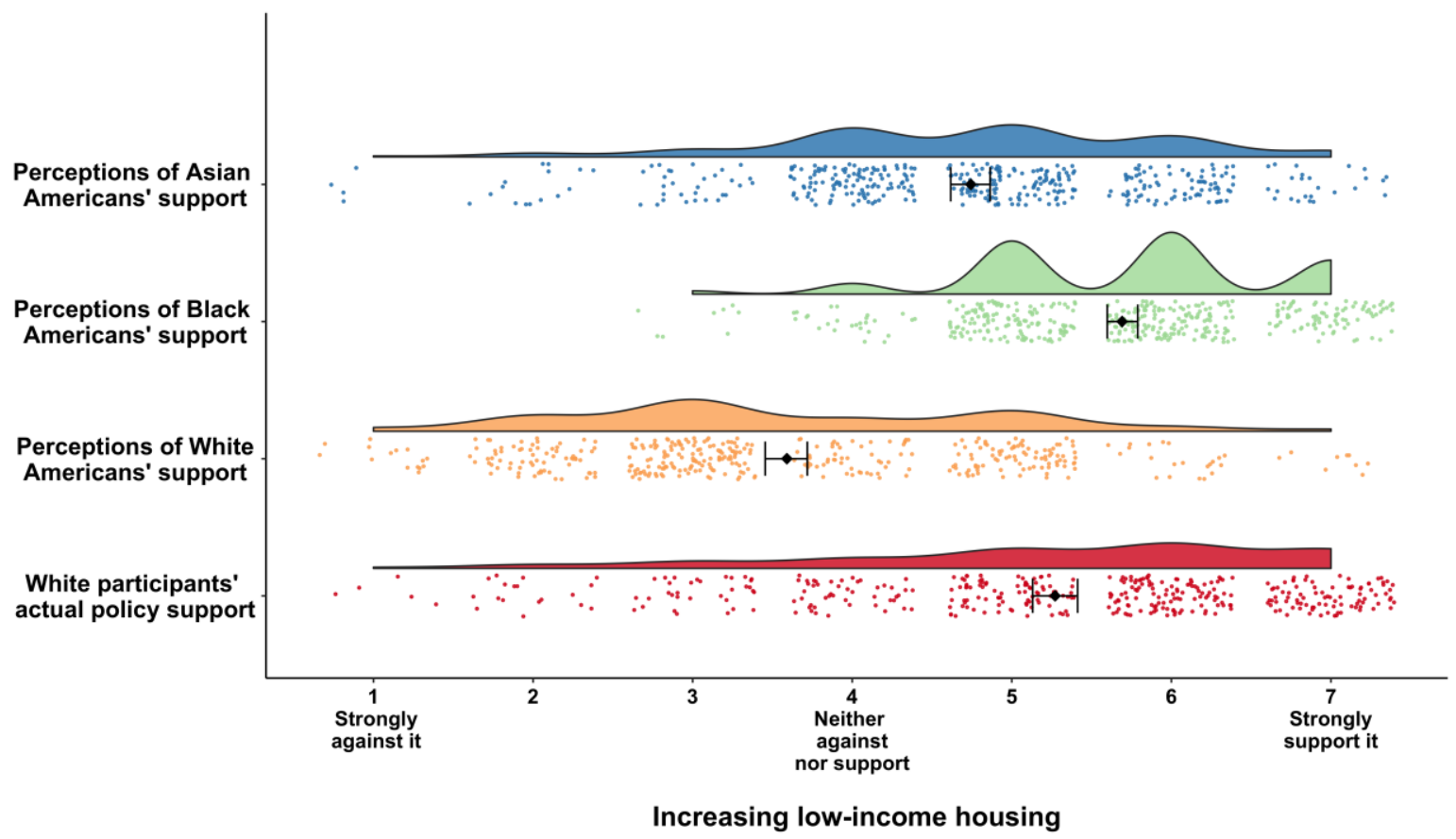

Figure 3. Raincloud plots with jittered data for White Americans' perceptions of Asian American, Black American, and White American attitudes toward increasing low-income housing. The lowest plot shows participants' own personal support of this issue. The colored dots and areas reflect the raw data and the data distributions. The black diamonds with error bars signify the means and $95 \%$ confidence intervals for each rating. 


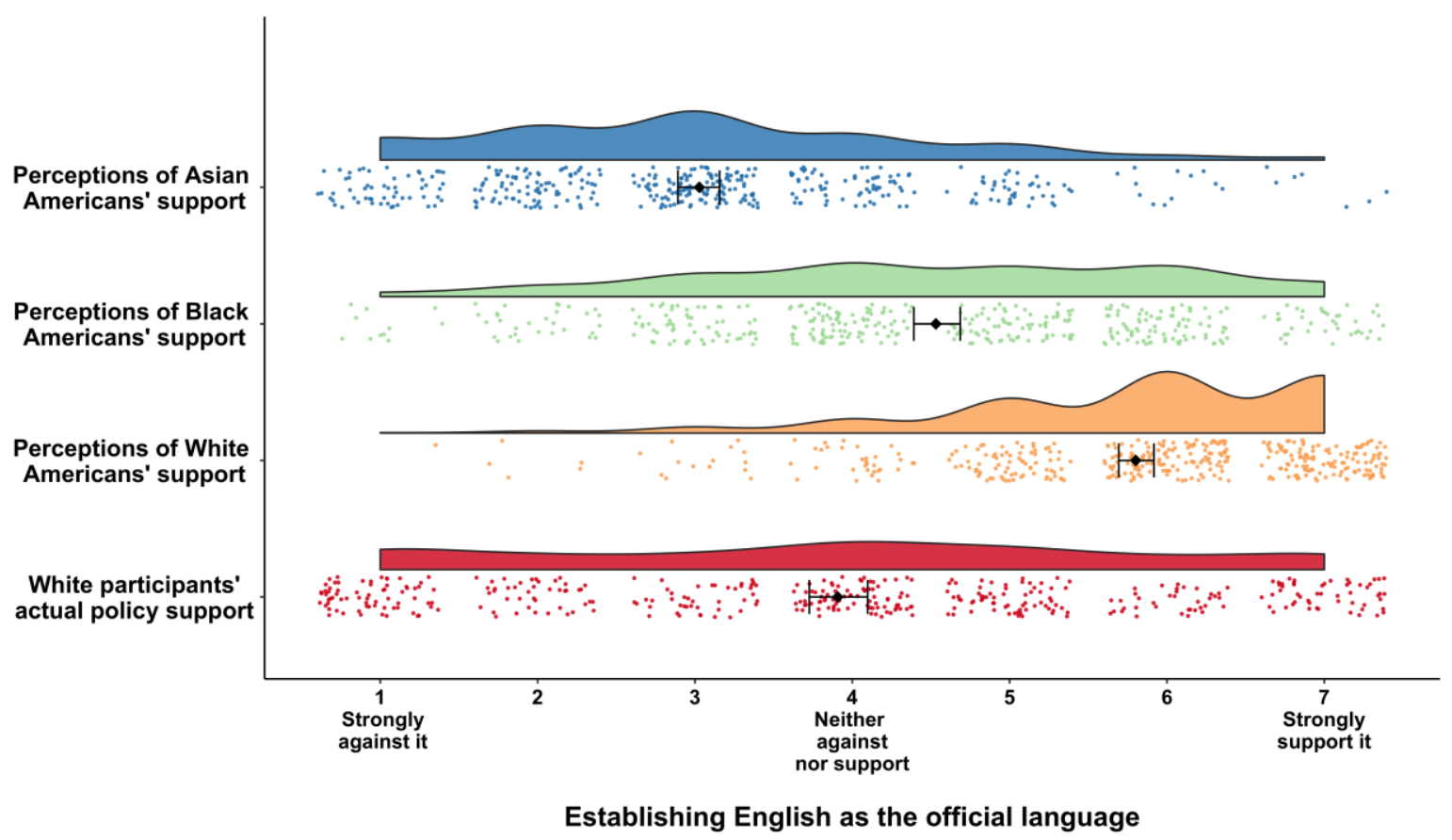

Figure 4. Raincloud plots with jittered data for White Americans' perceptions of Asian American, Black American, and White American attitudes toward making English the official language. The lowest plot shows participants' own personal support of this issue. The colored dots and areas reflect the raw data and the data distributions. The black diamonds with error bars signify the means and $95 \%$ confidence intervals for each rating. 


\section{Participants' Own Policy Support}

In contrast to their perceptions of Whites' attitudes, this sample of White participants generally supported increasing low-income housing and on average reported neither support nor opposition to making English the official language (see Figures 3-4 and Table 3). Generally, there was substantial variability in participants' support of both initiatives. 
Table 3. Descriptive statistics and zero-order correlations for White Americans' personal support of both initiatives and political decisions in Study 5 (English as the official language initiative above the diagonal, low-income housing initiative below the diagonal).

\begin{tabular}{|c|c|c|c|c|c|c|c|c|c|c|c|c|}
\hline \multirow[b]{2}{*}{ Variables } & \multicolumn{3}{|c|}{$\begin{array}{l}\text { English as the official language } \\
\text { (correlations above the diagonal) }\end{array}$} & \multicolumn{3}{|c|}{$\begin{array}{l}\text { Low-income housing } \\
\text { (correlations below the diagonal) }\end{array}$} & \multirow[b]{2}{*}{1} & \multirow[b]{2}{*}{2} & \multirow[b]{2}{*}{3} & \multirow[b]{2}{*}{4} & \multirow[b]{2}{*}{5} & \multirow[b]{2}{*}{6} \\
\hline & $M$ & {$[95 \% \mathrm{CI}]$} & $S D$ & $M$ & {$[95 \% \mathrm{CI}]$} & $S D$ & & & & & & \\
\hline 1. Participants' own support & 3.91 & {$[3.72,4.10]$} & 1.96 & 5.27 & {$[5.13,5.42]$} & 1.48 & - & $.24^{* * * *}$ & $.24^{* * *}$ & $.23^{* * * *}$ & -.01 & $-.15^{* *}$ \\
\hline $\begin{array}{l}\text { 2. Choice of voting method to } \\
\text { increase Black (vs. Asian) } \\
\text { influence }\end{array}$ & 0.43 & {$[0.38,0.48]$} & 0.50 & 0.73 & {$[0.69,0.77]$} & 0.44 & $.31^{* * *}$ & - & $.31^{* * *}$ & $.30^{* * *}$ & .07 & $-.13^{*}$ \\
\hline $\begin{array}{l}\text { 3. Choice to send volunteers } \\
\text { to the Black (vs. Asian) } \\
\text { community }\end{array}$ & 0.44 & {$[0.39,0.49]$} & 0.50 & 0.80 & {$[0.76,0.84]$} & 0.40 & $.23^{* * *}$ & $.31^{* * *}$ & - & $.61^{* * *}$ & $.21^{* * *}$ & $-.24^{* * *}$ \\
\hline $\begin{array}{l}\text { 4. Percentage of time to be } \\
\text { spent in the Black (vs. Asian) } \\
\text { community }\end{array}$ & 47.58 & {$[46.17,48.98]$} & 14.25 & 56.30 & {$[55.06,57.55]$} & 12.68 & $.15^{* *}$ & $.25^{* * *}$ & $.44^{* * *}$ & - & $.27^{* * * *}$ & $-.37^{* * *}$ \\
\hline $\begin{array}{l}\text { 5. Support for time spent in } \\
\text { the Black community }\end{array}$ & 4.64 & {$[4.53,4.76]$} & 1.20 & 5.00 & {$[4.89,5.10]$} & 1.08 & $.24^{* * *}$ & $.15^{* *}$ & $.23^{* * *}$ & $.35^{* * *}$ & - & $.28^{* * * *}$ \\
\hline $\begin{array}{l}\text { 6. Support for time spent in } \\
\text { the Asian community }\end{array}$ & 4.83 & {$[4.71,4.94]$} & 1.17 & 4.55 & {$[4.43,4.66]$} & 1.17 & $.12^{*}$ & -.05 & $-.14^{* *}$ & $-.28^{* * *}$ & $.42^{* * *}$ & - \\
\hline
\end{tabular}

Note. Correlations listed above the diagonal reflect associations among participants' own support of and political decisions regarding the initiative to make English the official language. Correlations listed below the diagonal reflect associations among participants' own support of and political decisions regarding the low-income housing initiative. ${ }^{*} p<.05 ;{ }^{* *} p<.01 ;{ }^{* * *} p<.001$. 


\section{Strategic Political Decision-making}

We predicted that people would strategically enhance the political voice of racial groups whom they viewed (based on racial-political stereotypes) as supportive of their own political preferences. To test this hypothesis, we correlated participants' own support for the initiatives with their support for resource allocation that would enhance the political influence of Black or Asian American voters. Consistent with predictions, White participants who were more supportive of increasing low-income housing (a relatively-liberal position on a status-relevant policy) were more likely to select the voting procedure, $r_{\text {point-biserial }}=.31,95 \% \mathrm{CI}[.21, .39], p<.001$, allocate more volunteers, $r_{\text {point-biserial }}=.23,95 \% \mathrm{CI}[.14, .33], p<.001$, and spend a greater percentage of time in the Black community, $r=.15,95 \% \mathrm{CI}[.05, .24], p=.003$, to enhance the political influence of Black Americans more than Asian Americans. Further, White participants who were more supportive of making English the official language (a relatively conservative position on an American identity-relevant policy) were also more likely to select a voting procedure, $r_{\text {point-biserial }}=.24,95 \% \mathrm{CI}[.14, .33], p<.001$, allocate more volunteers, $r_{\text {point-biserial }}=.24$, $95 \% \mathrm{CI}[.15, .33], p<.001$, and spend a greater percentage of time in the Black community, $r=.23$, 95\% CI[.13, .32], $p<.001$, to enhance turnout among Black Americans over Asian Americans. Examining the measure of how much time and effort should be devoted to each community separately, participants' support of low-income housing predicted the allocation of more time spent on turnout efforts in the Black community, $r=.24$, 95\% CI[.15, .33], $p<.001$, as well as, to a lesser extent, in the Asian American community, $r=.12,95 \% \mathrm{CI}[.02, .22], p=.014$. This latter, unexpected association may be explained by participants' perceptions that Asian Americans were somewhat supportive and benefited by the low-income housing initiative (i.e., 
ratings were significantly above the scale midpoint), possibly because the sample was drawn from an area with an economically-challenged Asian American refugee community.

Ratings for the American identity-relevant policy were fully consistent with expectations. Participants' support of making English the official language predicted allocating less time and effort to increasing Asian American voter turnout, $r=-.15,95 \% \mathrm{CI}[-.24,-.05], p=.004$, but there was no association between personal support and support for efforts to enhance Black turnout, $r=$ $-0.01,95 \% \mathrm{CI}[-.11, .09], p=.860$. Taken together, these results reveal that White Americans more strongly sought to influence the turnout of the group disadvantaged in a policy domain (Black Americans for a status-related policy, Asian Americans for an American cultural identity-related policy).

\section{Discussion}

Study 5 highlights one implication of stereotypic expectations of racial groups' policy attitudes: White Americans strategically enhanced the political voice of a racial group stereotyped as agreeing with their own attitudes (or suppressed the voice of a group perceived to disagree with their attitudes). For the status-related issue, the more that White participants supported a liberal position, the more they supported enhancing Black American voter turnout (vs. Asian American turnout). In contrast, the more that White participants held a liberal position on an issue seen as affecting American cultural identity, the more they supported enhancing voter turnout among the Asian American community (vs. Black American turnout). This pattern suggests that participants' racial-political stereotypes (i.e., expectations that Black Americans held liberal positions on status-related issues and more conservative positions on 
"Americanness"-related issues, and vice-versa for Asian Americans), more than participants' general ideological orientations, guided decisions to enhance turnout in different communities.

Complementing the results of the earlier studies, personal policy support in Study 5 more strongly predicted decisions regarding the racial group seen as disadvantaged in a domain (i.e., Black Americans for status and Asian Americans for American identity), perhaps because the disadvantaged minority groups' policy attitudes were perceived as more strongly held compared with the relatively-advantaged minority groups' (see Figures 3-4). Overall, Study 5 suggests that racial-political stereotyping may influence consequential political outcomes (e.g., voter suppression), regardless of these stereotypes' (in)accuracy.

\section{General Discussion}

The present research revealed that expectations for racial groups' political attitudes and interracial political coalitions are shaped by the degree to which the policy under consideration is viewed as impacting stereotyped dimensions of status and "Americanness." For policies seen as changing societal status (e.g., welfare), people assumed Black-Hispanic political coalitions and that Asian Americans were more likely to align with Whites than with other minorities. For policies seen as relating to American identity (e.g., immigration), however, people expected Asian-Hispanic coalitions and that Black Americans would align more with Whites than with other minorities. A novel group paradigm provided experimental evidence that such expectations stem from stereotypes about groups' societal status and "Americanness." The average policy preferences and voting patterns of members of different racial groups, however, did not follow stereotypical expectations, suggesting a disconnect between perceptions and the actual presence of interracial coalitions. Nevertheless, these racial-political stereotypes are potentially impactful 
because Whites strategically amplified (or suppressed) the political voice of racial minorities presumed to agree (or disagree) with their personal political views.

\section{Boundary Conditions and the Role of Discrimination Salience}

The present research found that individuals are more likely to perceive contextual coalitions based on the relevance of a policy to a stereotyped domain than they are to assume immutable intra-minority loyalty. How might one reconcile this nuanced pattern with prior research in which individuals expect broad minority solidarity? One key factor is likely the degree to which discrimination is salient (e.g., Craig \& Richeson, 2016; Fernández et al., 2014; Saguy et al., 2020; Warner \& Branscombe, 2012). In the present work, discrimination was not explicitly highlighted; rather, individuals were simply asked about racial groups' policy attitudes and likelihood of coalescing. In contrast, prior studies demonstrating expectations of solidarity among different stigmatized groups often explicitly make salient groups' experiences with discrimination (e.g., Fernández et al., 2014; Warner \& Branscombe, 2012). Indeed, it is telling that in the present studies, the only policies in which people more strongly anticipated a Whitevs.-minority dynamic were undocumented immigration (Study 2a), a policy whose national rhetoric has increasingly stigmatized undocumented immigrants (Dovidio et al., 2010; Morey, 2018), and affirmative action (Studies 1, 2b), a policy specifically designed to counter racial discrimination (EEOC, 1961).

Discrimination salience also plays a role in terms of whether groups actually express interracial solidarity. The results of Studies 2 and 4 suggest that political solidarity among members of different racial minority groups cannot be assumed to be automatically present in all political judgments (see also Benjamin, 2017; Craig \& Richeson, 2018). However, such solidarity may be more likely if individuals perceive that their discrimination experiences are 
shared (Cortland et al., 2017; Craig \& Richeson, 2012; Sanchez et al., 2018). Thus, a similar basic process likely drives perceptions of both nuanced, contextual and broad minority coalitions - expectations that disadvantaged groups will coalesce. Importantly, the present work suggests that in the realm of politics, the policy under consideration can shape the most salient form of group disadvantage (e.g., perceived foreignness or status) which adjusts expectations of interracial coalitions accordingly. Overall, perceptions of discrimination may play an important role in shifting both expectations of and actual support for different interracial coalitions.

\section{Panethnicity and the Divergence in Expectations and Actual Policy Preferences}

In the present work, consistent with most psychological research on U.S. race relations, groups were labeled at the panethnic level (groups composed of members of more than one national-origin group; e.g., Hispanic, Asian American; Okamoto, 2003). Across studies, people's expectations of groups' attitudes and behavior diverged from the actual expressed attitudes and behavior of people from those groups; this result may be informative for how social judgment occurs at this level of categorization. Specifically, these results are consistent with the possibility that observers base social judgments of panethnic categories on beliefs about the most numerically well-represented and cognitively-accessible national-origin group within that category (e.g., Chinese Americans for Asian Americans, Mexican Americans for Hispanic Americans). In contrast, the representative samples utilized in the present work include the diversity of national-origin groups that constitute these broader panethnic categories. Thus, while observers may use the most-accessible or prototypical ethnic group as a basis for judgment (e.g., Bruner, 1957), the averaged actual panethnic attitude indices collapse across a variety of national-origin groups with wide-ranging political preferences (e.g., AAPI, 2018; de la Garza et al., 1992). This suggests that individuals may not fully take into account the diversity within 
panethnic groups when making judgments of the broader category, potentially contributing to the observed discrepancies. Future work should test this empirically.

\section{Cross-racial Mobilization Revisited}

The present research may help psychologically situate prior work examining the circumstances in which voters support political candidates of different racial backgrounds (e.g., Benjamin, 2017; Boudreau et al., 2019). Past research (Benjamin, 2017) has revealed an asymmetry in the degree to which endorsements from ethnic ingroup leaders for a candidate of another race predicts support of minority or White candidates. Among Black and Hispanic voters, these co-ethnic endorsements garnered greater support for minority candidates (Hispanic and Black candidates, respectively) than for White candidates. The present studies may provide insight into this process, given the similar pattern in which stronger expectations of disadvantaged coalitions emerged than expectations that Whites would coalesce with intermediate-status minority groups. This suggests that violations of pre-existing expectations regarding interracial coalitions may, in part, explain minority voters' relative hesitancy to perceive Whites as suitable coalition partners (see also Lee \& Craig, 2021).

\section{Implications for Political Decision-making}

If people hold expectations for interracial coalitions that do not actually manifest, these expectations may nonetheless have consequences for future racial and political dynamics. Consistent with recent theorizing about the effects of anticipating increasing diversity on feelings of intergroup threat and prejudice (e.g., Craig et al., 2018), even anticipated coalitions may exacerbate intergroup tensions or lead individuals to take suboptimal strategies in their own political behavior. For example, perceiving political opposition from a large disadvantagedgroup coalition could have downstream consequences for perceived threat and expressed 
prejudice (see Blalock, 1967; Blumer, 1958) toward groups seen as forming an alliance antagonistic to one's own beliefs.

Racial-political stereotypes may also guide expectations that another racial group will support one's cause. For example, recent work has found that activating concerns about losing societal status can enhance Whites' expectations of political solidarity among stereotypically higher-status groups (e.g., White-Asian coalitions; Craig \& Lee, in press). Further, if under errant expectations of intergroup solidarity, this could reduce personal efforts to achieve a desired policy outcome (e.g., social loafing; Karau \& Williams, 1995). Or, consistent with the results of Study 5, individuals may allocate resources or attention (either positive or negative) to racial groups based on potentially unfounded assumptions of those groups' political beliefs. At an individual level, someone may decide to engage with different acquaintances about an upcoming election based on assumed political beliefs. At the state-level, research suggests that the implementation of restrictive voter identification laws may be strategic and enacted to improve relative turnout in favor of one's own Party (Hicks et al., 2015). The present research provides insight into an important element that people and Parties may consider if seeking to advance their political aims - the match between a salient policy and perceived support from different electorates.

\section{Conclusion}

The present research highlights how people think about U.S. racial groups' political attitudes, the veracity of these beliefs, and the consequences of racial-political stereotypes for decisions to influence different racial groups' political voices. White Americans strategically influenced the political sway of racial minorities based on (perhaps errant) expectations of policy 
preferences, which has consequential implications for intergroup relations and political dynamics in an increasingly diverse electorate. 


\section{References}

ANES (2018). American National Election Studies Time Series Cumulative Data File 1948-2016 [data file]. https://electionstudies.org/project/anes-time-series-cumulative-data-file/

AAPI (2018). Affirmative action: Good or bad thing? https://aapidata.com/infographic-2018affirmative-action-goodorbad/

Benjamin, A. (2017). Racial coalition building in local elections: Elite cues and cross-ethnic voting. Cambridge University Press.

Boudreau, C., Elmendorf, C.S., \& MacKenzie, S.A. (2019). Racial or spatial voting? The effects of candidate ethnicity and ethnic group endorsements in local elections. American Journal of Political Science, 63(1), 5-20.

Blalock, H.M. (1967). Toward a theory of minority-group relations. John Wiley.

Blumer, H. (1958). Race prejudice as a sense of group position. Pacific Sociological Review, 1, 3-7.

Bobo, L.D. (1999). Prejudice as group position: Microfoundations of a sociological approach to racism and race relations. Journal of Social Issues, 55(3), 445-472.

Borg, I., Groenen, P.J.F., \& Mair, P. (2018). Applied multidimensional scaling and unfolding (2nd ed.). Springer.

Bowen, W.G., \& Bok, D. (1998). The shape of the river: Long-term consequences of considering race in college and university admissions. Princeton University Press.

Browning, R.P., Marshall, D.R., \& Tabb, D.H. (1984). Protest is not enough: The struggle of Blacks and Hispanics for equality in Urban Politics. University of California Press.

Bruner, J.S. (1957). On perceptual readiness. Psychological Review, 64, 123-152. 
Caricati, L. (2018). Considering intermediate-status groups in intergroup hierarchies: A theory of triadic social stratification. Journal of Theoretical Social Psychology, 2(2), 58-66.

Chambers, J.R., Schlenker, B.R., \& Collisson, B. (2013). Ideology and prejudice: The role of value conflicts. Psychological Science, 24(2), 140-149.

Collingwood, L. (2020). Campaigning in a racially diversifying America: When and how crossracial electoral mobilization works. Oxford University Press.

Cortland, C.I., Craig, M.A., Shapiro, J.R., Richeson, J.A., Neel, R., \& Goldstein, N.J. (2017). Solidarity through shared disadvantage: Highlighting shared experiences of discrimination improves relations between stigmatized groups. Journal of Personality and Social Psychology, 113(4), 547-567.

Craig, M.A., \& Lee, M.M. (in press). Status-based coalitions: Hispanic growth affects Whites' perceptions of political support from Asian Americans. Group Processes and Intergroup Relations.

Craig, M.A., \& Richeson, J.A. (2012). Coalition or derogation? How perceived discrimination influences intraminority intergroup relations. Journal of Personality and Social Psychology, 102(4), 759-777.

Craig, M.A., \& Richeson, J.A. (2016). Stigma-based solidarity: Understanding the psychological foundations of conflict \& coalition among members of different stigmatized groups. Current Directions in Psychological Science, 25(1), 21-27.

Craig, M.A., \& Richeson, J.A. (2018). Hispanic population growth engenders conservative shift among non-Hispanic racial minorities. Social Psychological and Personality Science, 9(4), 383-392. 
Craig, M.A., Rucker, J.M., \& Richeson, J.A. (2018). The pitfalls and promise of increasing racial diversity: Threat, contact, and race relations in the 21 st century. Current Directions in Psychological Science, 27(3), 188-193.

de la Garza, R., DeSipio, L., Garcia, F.C., Garcia, J., \& Falcon, A. (1992). Latino voices: Mexican, Puerto Rican and Cuban perspectives on American politics. Westview.

Dovidio, J.F., Gluszek, A., John, M.S., Ditlmann, R., \& Lagunes, P. (2010). Understanding bias toward Latinos: Discrimination, dimensions of difference, and experience of exclusion. Journal of Social Issues, 66(1), 59-78.

EEOC (1961). Executive Order 10925: Establishing the President's Committee on Equal Employment Opportunity. https://www.eeoc.gov/eeoc/history/35th/thelaw/eo-10925.html

Fernández, S., Branscombe, N.R., Saguy, T., Gómez, A., \& Morales, J.F. (2014). Higher moral obligations of tolerance toward other minorities: An extra burden on stigmatized groups. Personality and Social Psychology Bulletin, 40(3), 1-14.

Fiske, S.T., Cuddy, A.J.C., Glick, P., \& Xu, J. (2002). A model of (often mixed) stereotype content: Competence and warmth respectively follow from perceived status and competition. Journal of Personality and Social Psychology, 82(6), 878-902.

Fulton, S.A., \& Gershon, S.A. (2018). Too liberal to win? Race and voter perceptions of candidate ideology. American Politics Research, 46(5), 909-939.

Furr, R.M., \& Rosenthal, R. (2003a). Repeated-measures contrasts for "multiple-pattern" hypotheses. Psychological Methods, 8, 275-293.

Furr, R.M., \& Rosenthal, R. (2003b). Evaluating theories efficiently: The nuts and bolts of contrast analysis. Understanding Statistics, 2, 45-67. 
Hicks, W.D., McKee, S.C., Sellers, M.D., \& Smith, D.A. (2015). A principle or a strategy? Voter identification laws and partisan competition in the American states. Political Research Quarterly, 68(1), 18-33.

Hutchings, V.L., \& Valentino, N.A. (2004). The centrality of race in American politics. Annual Review of Political Science, 7(1), 383-408.

Jacobsmeier, M.L. (2015). From Black and White to left and right: Race, perceptions of candidates' ideologies, and voting behavior in U.S. House elections. Political Behavior, $37,595-621$.

Jones, P.E. (2014). Revisiting stereotypes of non-White politicians' ideological and partisan orientations. American Politics Research, 42(2), 283-310.

Karau, S.J., \& Williams, K.D. (1995). Social loafing: Research findings, implications, and future directions. Current Directions in Psychological Science, 4(5), 134-140.

Koch, A., Imhoff, R., Dotsch, R., Unkelbach, C., \& Alves, H. (2016). The ABC of stereotypes about groups: Agency/socioeconomic success, conservative/progressive beliefs, and communion. Journal of Personality and Social Psychology, 110(5), 675-709.

Kim, C.J. (1999). The racial triangulation of Asian Americans. Politics \& Society, 27(1), 105138.

Kinder, D.R., \& Sanders L.M. (1996). Divided by color: Racial politics and democratic ideals. University of Chicago Press.

Lee, M.M., \& Craig, M.A. (2021). Perceptions of White allies' (ulterior) motives in raciallydiverse political coalitions. Manuscript in preparation.

Lindert, P.H. (2004). Growing public: Social spending and economic growth since the eighteenth century. Cambridge University Press. 
LA Times (1986). Los Angeles Times Poll: California General Election, Nov, 1986 [dataset]. USLAT1986-111, Version 1. Los Angeles Times [producer]. Roper Center for Public Opinion Research, RoperExpress [distributor], accessed Jul-25-2018.

LA Times (1994). Los Angeles Times Poll: California General Election Exit Poll, Nov, 1994 [dataset]. USLAT1994-350, Version 3. Los Angeles Times [producer]. Roper Center for Public Opinion Research, RoperExpress [distributor], accessed Jul-25-2018.

LA Times (1996). Los Angeles Times Poll: 1996 Exit Poll: National \& California, Nov, 1996 [dataset]. USLAT1996-389, Version 3. Los Angeles Times [producer]. Roper Center for Public Opinion Research, RoperExpress [distributor], accessed Jul-25-2018.

Masuoka, N., \& Junn, J. (2013). The politics of belonging: Race, public opinion, and immigration. University of Chicago Press.

McDermott, M.L. (1998). Race and gender cues in low-information elections. Political Research Quarterly, 51(4), 895-918.

Morey, B.N. (2018). Mechanisms by which anti-immigrant stigma exacerbates racial/ethnic health disparities. American Journal of Public Health, 108(4), 460-463.

National Election Pool (ABC News/Associated Press/CBS News/CNN/Fox News/NBC News) (2012). National Election Pool Poll \# 2012-STELEC-CA: California Election Day Exit Poll, Nov, 2012 [dataset]. USMI2012-STELEC-CA. Edison Media Research [producer]. Roper Center for Public Opinion Research, RoperExpress [distributor], accessed Jul-252018.

Okamoto, D.G. (2003). Toward a theory of panethnicity: Explaining Asian American collective action. American Sociological Review, 68(6), 811-842. 
Pew Research Center (2014, June 12). Political polarization in the American public. http://www.people-press.org/2014/06/12/political-polarization-in-the-american-public/ Rothschild, J.E., Howat, A.J., Shafranek, R.M., \& Busby, E.C. (2019). Pigeonholing Partisans: Stereotypes of Party Supporters and Partisan Polarization. Political Behavior, 41, 423443.

Saguy, T., Fernández, S., Branscombe, N.R., \& Shany, A. (2020). Justice agents: Discriminated group members are perceived to be highly committed to social justice. Personality and Social Psychology Bulletin, 46(1), 155-167.

Sanchez, D.T., Chaney, K.E., Manuel, S.K., \& Remedios, J.D. (2018). Theory of prejudice and American identity threat transfer for Latino and Asian Americans. Personality and Social Psychology Bulletin, 44(7), 972-983.

Schildkraut, D.J. (2003). American identity and attitudes toward official-English policies. Political Psychology, 24(3), 469-499.

Tichenor, D. (2002). Dividing lines: The politics of immigration control in America. Princeton University Press.

Visalvanich, N. (2017a). Asian candidates in America: The surprising effects of positive racial stereotyping. Political Research Quarterly, 70(1), 68-81.

Visalvanich, N. (2017b). When does race matter? Exploring white responses to minority congressional candidates. Politics, Groups, and Identities, 5(4), 618-641.

Warner, R.H., \& Branscombe, N.R. (2012). Observer perceptions of moral obligations in groups with a history of victimization. Personality and Social Psychology Bulletin, 38, 882-894.

Weiser, W.R., \& Feldman, M. (2018, June). The state of voting 2018. Brennan Center for Justice. Retrieved from 
https://www.brennancenter.org/sites/default/files/publications/2018_06_StateOfVoting_v $5 \% 20 \% 281 \% 29$.pdf

Winter, N.J.G. (2008). Dangerous frames: How ideas about race and gender shape public opinion. University of Chicago Press.

Zou, L.X., \& Cheryan, S. (2017). Two axes of subordination: A new model of racial position. Journal of Personality and Social Psychology, 112, 696-717. 